\title{
Imobilização de células microbianas e suas aplicações biotecnológicas
}

\section{Immobilizationofmicrobialcellsandtheirbiotechnologicalapplications}

\author{
Luiz Gustavo Covizzi; Ellen Cristine Giese; Eleni Gomes; \\ Robert F. H. Dekker; Roberto da Silva
}

\begin{abstract}
Resumo
O presente trabalho apresenta uma revisão sobre diferentes métodos e suportes utilizados para imobilizar células microbianas. Métodos de adsorção, engaiolamento e encapsulação de microrganismos estão discutidos, como também a imobilização natural. A utilização de procedimentos físicos e químicos para imobilização celular com o objetivo de aumentar a produtividade de metabólitos por bactérias, leveduras e fungos em processos fermentativos foi descrita assim como suas aplicações biotecnológicas na condição de biocatalizadores.

Palavras-chave: Imobilização Celular. Biocatalizadores. Suportes. Células Imobilizadas. Métodos de Imobilização Celular. Bioprocessos. Imobilização Natural.
\end{abstract}

\begin{abstract}
This work presents an overview of different methods and carriers used to immobilize microbial cells. Methods of adsorption, entrapment and encapsulation of microorganisms are discussed, as well as of natural immobilization. The use of physical and chemical proceedings to immobilize cells in order to enhance the yields of bacteria, yeast and fungal metabolites by fermentation processes are described, as well as their biotechnological applications as biocatalystis.

Key words: Cell Immobilization. Biocatalystis. Carriers. Immobilized Cells. Methods of Cell Immobilization. Bioprocesses. Natural Immobilization.
\end{abstract}

\section{Introdução}

O estado morfológico do microrganismo durante o processo fermentativo influencia diretamente a obtenção dos produtos microbianos de interesse, por diminuir o tempo de cultivo e aumentar o rendimento do processo (FENG et al., 2003). Os fungos, por exemplo, apresentam uma morfologia bastante complexa com estruturas celulares diferentes em cada etapa do seu ciclo de vida (PRASAD et al., 2005).
Uma das alternativas encontradas para "engenheirar" a estrutura morfológica destes microrganismos é a imobilização celular (IC), de maneira que seja preservada a atividade catalítica desejada, para aplicação tanto em escala de laboratório quanto industrial. A tecnologia da IC se restringe à produção de metabólitos extracelulares ou a utilização de microrganismos como biocatalizadores (KOURKOUTAS et al., 2004; PRASAD et al., 2005), conforme a Tabela 1.

1 Mestre em Engenharia e Ciências de Alimentos, UNESP, S. J. Rio Preto-SP, lgcovizzi@gmail.com.

2 Doutoranda em Engenharia e Ciências de Alimentos, UNESP, S. J. Rio Preto-SP, ellengiese@gmail.com.

3 Professor Assistente Doutor do Departamento de Biologia, UNESP, S. J. Rio Preto-SP, eleni@ibilce.unesp.br.

4 Pesquisador Visitante CNPq, Departamento de Bioquímica e Biotecnologia, UEL, Londrina-PR. Endereço atual: Universidad de Castilla-La Mancha, IRICA, 13071 Ciudad Real, España, Robert.Dekker@uclm.es.

5 Professor Adjunto do Departamento de Química e Ciências Ambientais, UNESP, S. J. Rio Preto-SP, dasilva@ibilce.unesp.br. 
A IC consiste no confinamento físico das células em uma região definida de espaço, na qual são mantidas suas atividades catalíticas em processos de operação contínua ou descontínua possibilitando a reutilização das mesmas. A maioria dos processos fermentativos industriais convencionais utiliza células livres em suspensão, porém o uso de microrganismos imobilizados (MI) permite um aumento da produtividade devido à elevada concentração de células. (FREEMAN; LILLY, 1998).
A maior concentração de células microbianas no suporte garante a síntese dos metabólitos e aumenta a eficiência da fermentação. Além disso, facilita a recuperação dos produtos do metabolismo de interesse na fase de "downstream" e ajuda na manutenção dos fermentadores, uma vez que não apresenta problemas de adesão e obstrução aos eletrodos e tubos (MOREIRA et al., 1998; KOURKOUTAS et al., 2004; BERGMAIER; CHAMPAGNE; LACROIX, 2005).

Tabela 1. Aplicações de microrganismos imobilizados e suportes utilizados em processos biotecnológicos.

\begin{tabular}{|c|c|c|c|}
\hline Processo & Microrganismo & Suporte utilizado & Referência \\
\hline \multirow{2}{*}{ Produção de pigmentos } & M. purpureus & alginato, PUF, carvão, perlita & FENICE et al., 2000 \\
\hline & G. fujikuroi & alginato & GARBAYO et al., 2003 \\
\hline Produção de proteínas & S. cerevisiae & PVA & PARASCANDOLA; BRANDUARDI; ALTERIIS, 2006 \\
\hline \multirow{3}{*}{ Produção de exopolissacarídeos } & L. rhamnosus & silicone & BERGMAIER; CHAMPAGNE; LACROIX, 2005 \\
\hline & Beijerinckia sp. & maltodextrina & BOZA; COSTA; SCAMPARINI, 2004 \\
\hline & A. pullulans & agar, alginato & WEST; STROHFUs, 2001 \\
\hline \multirow{8}{*}{ Produção de enzimas } & N. frowardii & PUF & ROGALSKI et al., 2005 \\
\hline & H. lutea & $\begin{array}{l}\text { PVA-MAA/PEG; PVA-MAA/ } \\
\text { alginato de cálcio }\end{array}$ & $\begin{array}{l}\text { ALEKSIEVA; PETRICHEVA; KONSTANTINOV, } \\
\text { 1998; SLOKOSKA et al., } 1999\end{array}$ \\
\hline & Aspergillus sp. & CrioPAG $^{\circledR}$ & LUSTA et al., 2000 \\
\hline & P. chrysosporium & $\begin{array}{l}\text { PUF, aço inoxidável, cerâmica, } \\
\text { náilon, poliestireno }\end{array}$ & $\begin{array}{l}\text { GERIN; ASTHER; ROUXHET, 1997; COUTO et al., } \\
\text { 2000; SHIM; KAWAMOTO, } 2002\end{array}$ \\
\hline & Agaricus sp. & PUF & KALUSKAR et al,. 1999 \\
\hline & A. niger & alginato & ANGELOVA; SHEREMETSKA; LEKOV, 1995 \\
\hline & P. ostreatus & PUF & PRASAD et al., 2005 \\
\hline & T. turnirae & alginato & BESHAY, 2003 \\
\hline \multirow{3}{*}{ Biotransformação } & R. minuta & agar, clara de ovo, lã de vidro/PEI & VELANKAR; HEBLE, 2003 \\
\hline & T. versicolor & náilon & SEDARATI et al., 2003 \\
\hline & Rhodococcus sp. & alginato & GUO et al., 2006 \\
\hline \multirow{6}{*}{ Biodegradação } & Bacillus sp. & alginato, PUF & PATIL et al., 2006 \\
\hline & F. trogii & alginato & PARK et al., 2006 \\
\hline & P. stutzeri & alginato, areia, carvão & VIGGIANI et al., 2006 \\
\hline & E. coli e B. subtilis & auto-imobilização & YASUDA et al., 2003 \\
\hline & P. chrysosporium & PUF, cerâmica, serragem & SHIM; КАWAMOTO, 2002 \\
\hline & Rhodococcus sp. & alginato, carvão & PAI et al., 2005 \\
\hline Redução de sulfatos & Bactérias & PUF, $\mathrm{PE}, \mathrm{Al}_{2} \mathrm{O}_{3}$ & SILVA et al., 2006 \\
\hline Fermentação demostos de uvas & S. cerevisiae & maçã & KOURKOUTAS et al., 2004 \\
\hline Produção de vinhos doces & K. marxianus & maçã & KOURKOUTAS et al., 2004 \\
\hline Produção de leite fermentado & L. casei & alginato, maçã & KOURKOUTAS et al., 2004 \\
\hline
\end{tabular}




\begin{tabular}{|c|c|c|c|}
\hline Produção de ácido lático & L. casei & bucha vegetal & KOURKOUTAS et al., 2004; \\
\hline Produção de sorbitol & Z. mobilis & bucha vegetal & VIGNOLI; CELLIGOI; SILVA, 2006 \\
\hline Produção de etanol & S. cerevisiae & bucha vegetal & OGBONNA; MASHIMA, TANAKA, 2001 \\
\hline Produção de antibióticos & S. clavuligerus & alginato, náilon & DEVI; SRIDHAR, 2000 \\
\hline \multirow{2}{*}{ Descoloração de melanoidinas } & C. hirsutus, & PUF & FUJITA et al., 2000 \\
\hline & G. candidum & PUF & KIM; SHODA, 1999 \\
\hline \multirow[b]{2}{*}{ Solubilização de fosfatos } & A. niger & PUF & VASSILEV; VASSILEVA; AZCON, 1997 \\
\hline & $\begin{array}{c}\text { Chlorella spp. , e A. } \\
\text { brasilense }\end{array}$ & co-imobilização & HERNANDEZ; DE-BASHAN; BASHAN, 2006 \\
\hline $\begin{array}{l}\text { Produção de peptídeos para } \\
\text { controle de pragas }\end{array}$ & M. anisopliae & auto-imobilização & FENG et al., 2003 \\
\hline $\begin{array}{l}\text { Produção de auxina e ácido } \\
\text { abscísico }\end{array}$ & P. chrysosporium & PUF & ÜNYAYAR; ÜNYAYAR; ÜNAL, 2000 \\
\hline
\end{tabular}

*PVA: álcool polivinílico; PUF: fibra de poliuretano; MAA: N-metileno acrilamida; PEG: polietilenoglicol; CrioPAG espuma de poliestireno não-trançada; PEI: polietilenoimina; PE: polietileno

A reutilização das células imobilizadas é considerada uma das grandes vantagens da IC, principalmente quando os suportes escolhidos para imobilização são inertes e apresentam alta resistência mecânica, como na produção de Cefamicina C por Streptomyces clavuligerus, imobilizado em esponja de náilon, e na produção de enzimas por Phanerochaete chrysosporium, imobilizado em espuma de poliuretano (COUTO et al., 2000), (DEVI; SRIDHAR, 2000).

O aprimoramento e o desenvolvimento de novas técnicas de IC, associadas ao uso de novos materiais como suporte, têm permitido que os processos fermentativos com células imobilizadas sejam realizados em condições adversas de $\mathrm{pH}$, de esterilidade e agitação. O emprego de células livres não seria possível, em meios de cultivo mais tóxicos, como por exemplo, no tratamento de águas residuais contaminadas com fenóis e derivados (JUNTER; JOUENNE, 2004; WANG et al., 2005).

A IC surgiu como alternativa à imobilização de enzimas, pois não requer etapas de extração, isolamento e purificação. Desde então, o processo de imobilização tem conseguido vários avanços, principalmente na área da biotecnologia, permitindo a obtenção de metabólitos microbianos de maneira mais eficiente. $\mathrm{O}$ interesse por esta técnica pode ser avaliado pelo crescente número de artigos e resenhas publicados, citando-se a palavra-chave “imobilização celular”, como mostra a Figura 1.

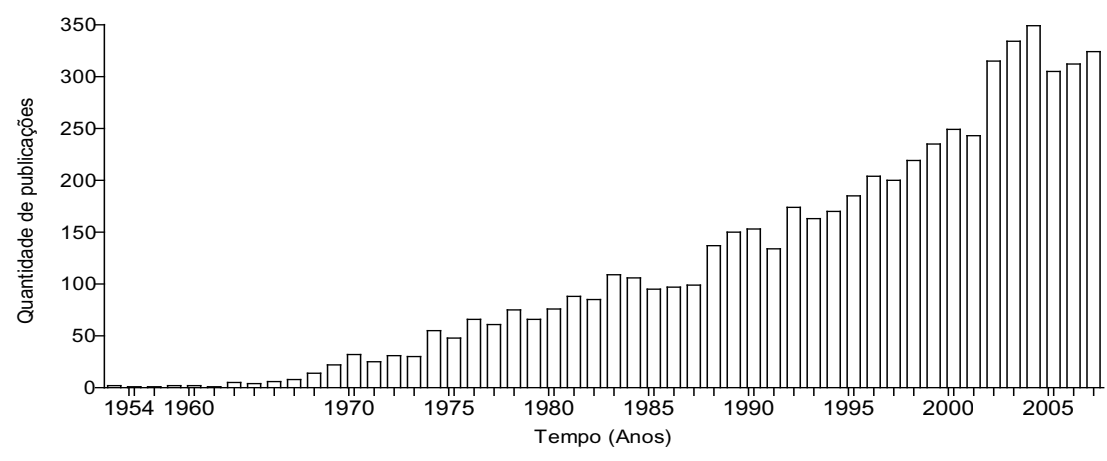

Figura 1. Evolução do número de publicações científicas em periódicos internacionais indexados, referentes ao termo "imobilização celular", nos últimos 50 anos (Fonte: Web of Science Data Base "on-line"). 
As técnicas clássicas de IC podem ser classificadas em: a) naturais, as quais incluem a formação de biofilmes e a adesão/adsorção microbiana em suportes sintéticos ou naturais, e b) artificiais, as quais incluem a encapsulação em matrizes como alginato de cálcio ou uso de agentes ligantes.

A imobilização natural ocorre espontaneamente por meio de interações eletrostáticas. Já no caso da imobilização artificial, as células são ligadas às matrizes por ligações covalentes, utilizando-se agentes ligantes como glutaraldeído ou carbodiimida. A célula permanece viável independente dos possíveis danos causados pelo procedimento. A Figura 2 ilustra os diferentes tipos de IC utilizadas em pesquisas e em plantas industriais.

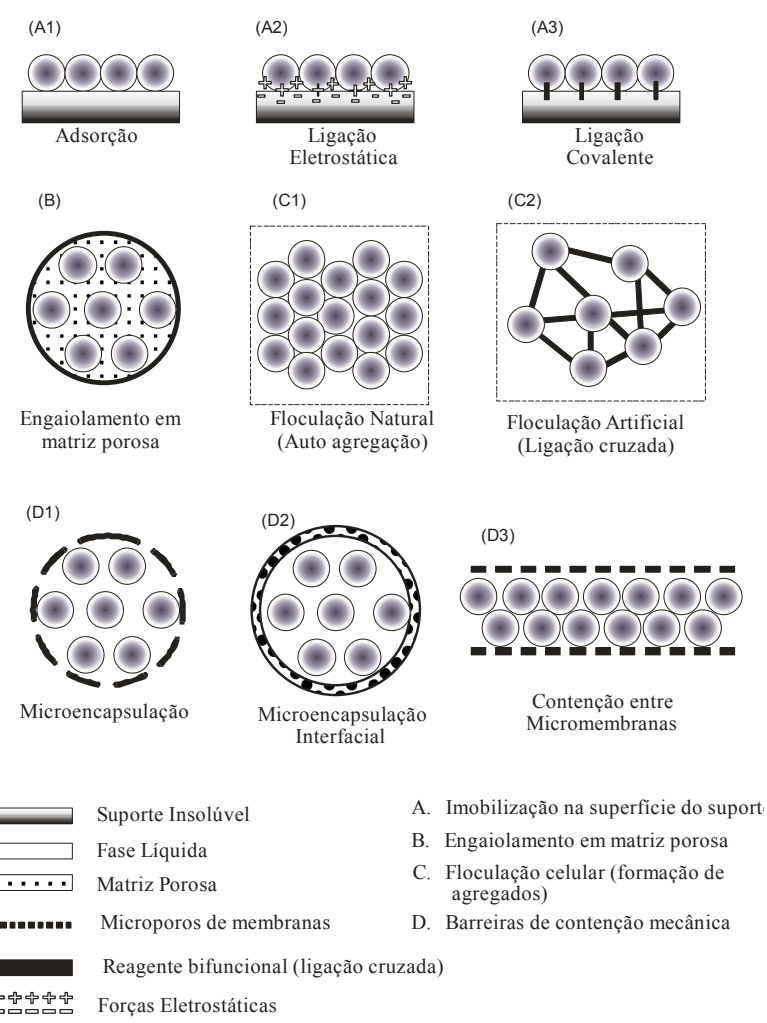

Figura 2. Diferentes métodos de imobilização celular de microrganismos, adaptado de Pilkington et al. (1998).

Embora apresente algumas desvantagens, o uso de células microbianas imobilizadas é compensado pelas vantagens que o método proporciona. O processo de imobilização pode não ser econômico e as limitações de transferência de massa podem afetar a fisiologia e cinética do crescimento celular. Além disso, a matriz utilizada pode romper-se devido ao crescimento celular e evolução de gases, devido às limitações na transferência de oxigênio (WANG et al., 2005). Assim, para que a IC apresente sucesso, é necessário escolher adequadamente a metodologia a ser utilizada.

A IC também representa uma alternativa ao uso dos sistemas sólidos de fermentação. Os processos que empregam MI podem ser realizados em espaço físico menor, como em biorreatores, ocorrem em ambientes com maior atividade de água e permitem melhor controle de contaminações (DOMÍNGUEZ; COUTO; SANROMÁN, 2001).

O Monascus purpureus, por exemplo, é produtor de pigmentos intracelulares sob fermentação submersa, os quais são secretados para o meio quando cultivado em estado sólido. Porém, o uso de resíduos agrícolas, como casca de arroz, dificulta a recuperação do pigmento do meio de cultivo e o emprego de MI foi uma maneira encontrada para recriar as condições fisiológicas do estado sólido, resultando ainda no aumento de produtividade (FENICE et al., 2000).

A eficiência do suporte no processo de IC pode ser avaliada pela capacidade da matriz em alojar a maior quantidade de células viáveis possível, sem limitar a transferência de massa entre o microrganismo e o meio de cultivo.b

Diferentes métodos de IC têm sido utilizados na obtenção de sistemas eficientes para utilização nos processos fermentativos em reatores industriais, tornando-os economicamente viáveis e apresentando melhor produtividade. Porém, a escolha de uma matriz adequada para a imobilização das células é de fundamental importância para a obtenção do produto desejado, sendo esta escolha peculiar para cada microrganismo e metabólito estudado (PETRE et al., 1999) (Tabela 2). O tamanho do poro, a porosidade e o grau de hidrofobicidade da matriz interferem na intensidade da adesão celular (SILVA et al., 2006). 
Tabela 2. Características ideais desejáveis para a matriz ou suporte selecionado para imobilizar células microbianas.

\begin{tabular}{|c|c|}
\hline Características & Referências \\
\hline Ter grande área superficial com espaço intersticial para o crescimento celular. & DEVI S, SRIDHAR, 2000 \\
\hline Possuir grupos funcionais ligantes, no caso de adesão artificial. & FREEMAN; LILLY, 1998 \\
\hline Ser facilmente regenerável e possível de reuso. & $\begin{array}{l}\text { CHAMPAGNE; LACROIX; SODINI- } \\
\text { GALLOT, } 1994\end{array}$ \\
\hline $\begin{array}{l}\text { Proporcionar a viabilidade celular e atividade catalítica, por um longo período de } \\
\text { tempo. }\end{array}$ & GARBAYO et al., 2003 \\
\hline $\begin{array}{l}\text { Apresentar porosidade uniforme a fim de permitir trocas gasosas, entrada de substrato } \\
\text { e fluxo de cofatores e produtos do metabolismo microbiano. }\end{array}$ & NORTON et al., 1994 \\
\hline Ter boa estabilidade mecânica, química, térmica e biológica. & DíAz et al., 2001 \\
\hline Não ser degradável facilmente por enzimas ou solventes envolvidos no processo. & $\begin{array}{l}\text { BERGMAIER; CHAMPAGNE; } \\
\text { LACROIX, } 2005\end{array}$ \\
\hline Ser estável a mudanças drásticas de pressão, temperatura e pH do meio. & MOREIRA et al., 1998 \\
\hline Proporcionar imobilização fácil, acessível e viável para uso em escala industrial. & FENICE et al., 2000 \\
\hline
\end{tabular}

\section{Imobilização de células microbianas por adsorção em suportes sólidos}

As primeiras pesquisas acerca imobilização de células microbianas surgiram a partir das observações da habilidade de alguns microrganismos se fixarem naturalmente em superfícies de diferentes ambientes, desde caules de árvores, como no caso de microrganismos fitopatogênicos, até cateteres hospitalares, em se tratando de bactérias oportunistas. A colonização da superfície por formação de biofilmes é uma estratégia universal das bactérias para a sobrevivência e pode ocorrer naturalmente, como no caso das bactérias formadoras da cárie, ou até mesmo em instalações industriais, por exemplo (JUNTER; JOUENNE, 2004).

Os fungos filamentosos são microrganismos eucarióticos amplamente aplicados em processos fermentativos em indústrias, visando principalmente à produção de enzimas de interesse comercial (WANG et al., 2005). Para a IC destes fungos, utilizam-se suportes porosos visto que ocorre adesão das células microbianas à superfície do suporte. Quando os poros são maiores, as células em crescimento (hifas) penetram no suporte, preenchendo seu espaço interno. Este método de imobilização também se utiliza da habilidade de os microrganismos produzirem e secretarem exopolissacarídeos (EPS) (PRASAD et al., 2005).

Um dos problemas deste tipo de imobilização está relacionado com a formação e acúmulo de biofilme ou EPS sobre a superfície, o que dificulta a absorção de nutrientes resultante das condições nãohomogêneas do crescimento celular. Os produtos secretados para o meio extracelular têm sua difusão dificultada e a troca gasosa também pode ser comprometida (XAVIER et al., 2003).

A produção de EPS por células microbianas imobilizadas em suportes porosos também tem sido descrita. Porém, como a secreção de EPS para o meio aumenta excessivamente a viscosidade do mesmo, o uso da IC é limitado para alguns tipos de microrganismos, de acordo com o comportamento reológico do meio de cultivo e o tipo de matriz utilizada (BERGMAIER; CHAMPAGNE; LACROIX, 2005).

Aproduçãodepululanapelo fungo Aureobasidium pullulans, por exemplo, apresentou maior rendimento quando uma espuma de poliuretano foi utilizada como suporte, em comparação com cubos de agar ou de alginato de cálcio, devido às dificuldades na transferência de massa causadas por estes últimos (WEST; STROHFUS, 2001). 
A produção de lacases pelo Coriolopsis rigida também foi aumentada significativamente quando este basidiomiceto foi imobilizado em espuma de poliuretano (SAPARRAT et al., 2002). A produção de manganês-peroxidase por micélios livres e imobilizados de Nematoloma frowardii, neste mesmo suporte, foi comparada e os cultivos com células imobilizadas apresentaram maior atividade enzimática do que os com células livres (ROGALSKI; SZCZODRAK; JANUZ, 2005). O mesmo fenômeno também foi observado na produção de lacases pelo fungo Agaricus sp., que aumentou 13 vezes a produção de lacase (KALUSKAR et al., 1999).

As espumas de poliuretano como suportes para a IC têm sido utilizados na produção de ácidos orgânicos, na solubilização simultânea de fosfato inorgânico por rhizobactérias e fungos micorrízicos em solos, sendo uma alternativa aos fertilizantes químicos (VASSILEV; VASSILEVA; AZCON, 1997), (VASSILEV et al., 2001). Também têm sido utilizadas na produção de substâncias vinculadas à fisiologia de plantas, como a auxina e o ácido abscísico (ÜNYAYAR; ÜNYAYAR; ÜNAL, 2000).

Alguns materiais alternativos têm sido empregados como suportes para imobilizar microrganismos como pedaços de maçã para imobilizar Saccharomyces cerevisiae em processos de vinificação. Esta é uma alternativa de baixo custo e compatível com o aroma e sabor dos vinhos (KOURKOUTAS et al., 2001). Peças de cerâmicas têm sido utilizadas como suporte para a Candida tropicalis no tratamento de resíduos ricos em carboidratos procedentes de indústrias alimentícias, e, peneiras de aço inoxidável, são utilizadas para imobilizar células de $P$. chrysosporium, visando à produção de peroxidases (GERIN; ASTHER; ROUXHET, 1997).

Uma esponja de celulose como a Luffa cylindrica (bucha vegetal), foi utilizada para a imobilização de Zymomonas mobilis para a produção de sorbitol (VIGNOLI; CELligOI; SILVA, 2006) e de $S$. cerevisiae (OGBONNA; MASHIMA; TANAKA,
2001), para produzir etanol. Grãos de cevada foram citados como suporte na produção de pectinases por Kluyveromyces marxianus (ALMEIDA et al., 2003). Outros exemplos de matrizes sólidas são DEAE-celulose, madeira, serragem, bagaço de cana de açúcar, e materiais inorgânicos como rochas, porcelanas e vidros porosos (DOMÍNGUEZ; COUTO; SANROMÁN, 2001).

O método de adsorção é utilizado pela sua simplicidade, baixo custo, fácil manipulação e grande diversidade de suportes. Há um potencial de equilíbrio entre as células adsorvidas e livres, dependendo do crescimento microbiano e da densidade de células na matriz. A equação 1 representa este equilíbrio entre as células livres $\left(C_{\text {livres }}\right)$ e adesão no suporte $(S)$ e as células enfim imobilizadas $\left(C_{\text {imobilizadas }}\right)$. Pode observar-se na Figura 3 , que o ponto de equilíbrio ocorre no início da fase estacionária de adsorção das células.

$$
C_{\text {livres }}+S \leftrightarrow C_{\mathrm{m} \text { obilizadas }}
$$

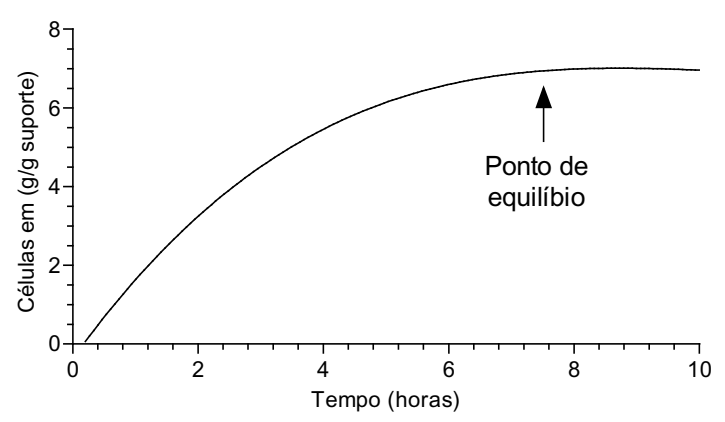

Figura 3. Equilíbrio entre células livres e imobilizadas no suporte pelo princípio de adsorção.

A grande vantagem da IC para a produção de enzimas é que este sistema permite a produção contínua e eficiente destas proteínas pelos microrganismos, por um longo período de tempo (DOMÍNGUEZ; COUTO; SANROMÁN, 2001). Quando se utilizam células livres, ocorre um pico de atividade enzimática e, no caso do uso de 
microrganismos imobilizados, ocorre um platô de atividade que pode durar por um período mais longo (PRASAD et al., 2005). O uso de esporos neste tipo de imobilização não é recomendável, uma vez que a agregação destes sobre a superfície do suporte é muito lenta e, em alguns casos, após o processo de imobilização, o fungo cresce na forma de "pellets" e fica disperso no meio de cultivo (GERIN; ASTHER; ROUXHET, 1997).

\section{Encapsulação e engaiolamento de células microbianas em matrizes}

O método de engaiolamento está baseado na inclusão artificial das células, que ficam inseridas em uma malha rígida, ou semi-rígida, que impede a difusão destas para o meio de cultivo. Este aprisionamento do microrganismo possibilita a troca de nutrientes, metabólitos, gases durante o processo fermentativo. A diferença entre este método e o de encapsulação é que, neste último, as células ficam apenas envoltas por uma membrana e não há uma malha entre as células por ela envolvidas. (CHAMPAGNE; LACROIX; SODINI-GALLOT, 1994; KRISHNAN et al., 2001).

O mecanismo clássico de imobilização por engaiolamento é a mistura de células microbianas com um composto polimérico que apresenta cargas negativas (alginato, pectato, ou outro polímero orgânico com cargas negativas). Esta mistura é gotejada em uma solução com íons $\mathrm{Ca}^{2+}$, por exemplo, conforme ilustra a Figura 4. O íon $\mathrm{Ca}^{2+}$ promove a formação de ligações iônicas, que resultam na formação de um gel consistente e insolúvel, o qual imobiliza o microrganismo. $\mathrm{O}$ tamanho da barreira de contenção formada em torno das células irá depender da velocidade de fluxo, da densidade da solução polimérica e da concentração da solução iônica, na qual o gel será formado. No processo de encapsulação, as células microbianas são colocadas em uma solução de cloreto de cálcio, que é gotejada a posteriori na solução polimérica, na qual será formada a cápsula envoltória (WANG et al., 2005).

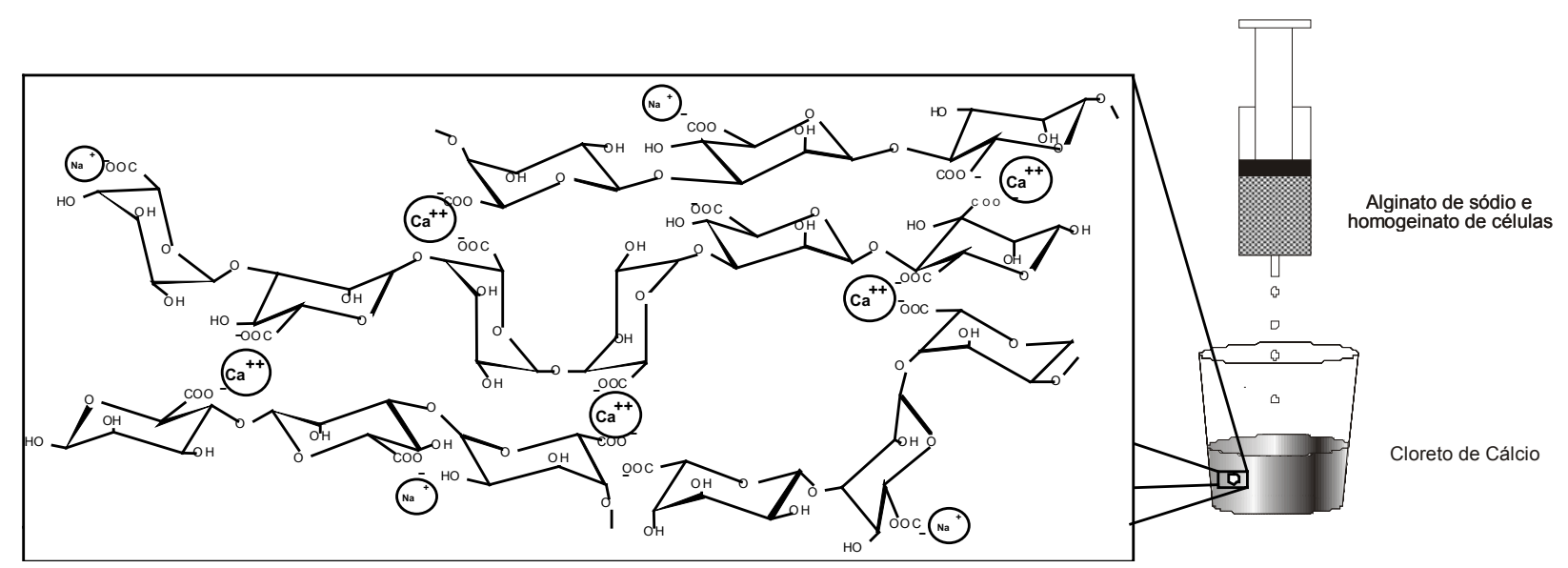

Figura 4. Formação do gel de alginato de cálcio por engaiolamento.

O crescimento celular nestes tipos de IC depende da limitação imposta pela porosidade do material e do acúmulo de biomassa no interior da matriz. São vários os géis utilizados como: ágar, agarose, goma carragenana, alginato e quitosana, além de géis como o álcool polivinílico (PARASCANDOLA; BRANDUARDI; ALTERIIS, 2006).
A imobilização de células microbianas em géis de alginato tem sido a mais utilizada em processos fermentativos, envolvendo bactérias, leveduras, e mais raramente, fungos. Como exemplo, pode ser citada a produção de ácido lático por Lactobacillus casei (YOO et al., 1996) e de carotenóides pelo fungo filamentoso Giberella fujikuroi (GARBAYO et al. 2003). 
O alginato é um polissacarídeo linear constituído por unidades de ácido manurônico ligado por ligações glicosídicas do tipo $\beta(1 \rightarrow 4)$, e também, por unidades de ácido gulurônico, unidas por ligações do tipo $\alpha(1 \rightarrow 4)$ (guo et al., 2006). Porém, os géis de alginato de cálcio (Figura 4) são quimicamente instáveis na presença de alguns componentes do meio de cultivo, como íons fosfato e citrato, podendo sofrer rupturas ou até mesmo dissolveremse no meio. Este problema tem sido contornado com o uso de sais de bário, no lugar do cálcio ou pelo tratamento com quitosana, para aumentar a resistência (YOO et al., 1996).

É importante ressaltar a limitação de transferência de massa imposta aos processos de IC em géis. Geralmente, a quantidade de $\mathrm{O}_{2}$ que adentra às microesferas do gel de carragenana é estimada na faixa de 0,08 a $0,1 \mathrm{~mm}^{3}$, enquanto que em géis de alginato, estes valores são um pouco maiores (de 0,1 a $0,16 \mathrm{~mm}^{3}$ ) (OGBONNA et al., 2000).

A distribuição de $\mathrm{O}_{2}$ é importante, à medida que favorece estados metabólicos diferentes, na população de microrganismos imobilizados na microesfera de gel, o que resulta na formação de uma população microbiana não-homogênea, com diferenciações celulares na superfície e no interior da matriz (FREEMAN; LILLY, 1998).

Uma aeração não-uniforme pode ocasionar a migração das células da superfície da matriz de contenção para o meio externo e o conseqüente rompimento da matriz do gel, sendo esse um dos maiores problemas encontrados neste tipo de imobilização.

Serp et al. (2000) avaliaram o efeito de uma dupla camada de gel na matriz pré-formada, para prevenir o rompimento; entretanto, apesar de ter formado um núcleo celular que impediu que as células microbianas escapassem do seu interior, a dupla camada dificultou a difusão de $\mathrm{O}_{2}$ e mostrouse ineficiente como técnica de imobilização.

É difícil quantificar a biomassa microbiana imobilizada por meio de contenção em barreiras, tornando-se um outro problema nestes métodos de IC em processos biotecnológicos. Atualmente, métodos como a gravimetria, determinação de proteínas totais e a quantificação de NADH têm sido associado à concentração celular no interior das matrizes. Navratil et al. (2000) propuseram um método baseado na luminescência, por meio da determinação de ATP, como um método rápido e eficiente para a determinação da biomassa microbiana em géis de alginato, pectato de cálcio e goma carragenana.

Para evitar os problemas causados pela instabilidade dos géis tradicionais nos caldos fermentativos, muitos segmentos industriais e pesquisadores vêm optando pelo uso do álcool polivinílico (PVA), um polímero atóxico e mais resistente, pois não depende de ligações iônicas. O gel de PVA pode ser estável em temperaturas relativamente altas, de até $80^{\circ} \mathrm{C}$, dependendo do agente ligante utilizado no processo. A colonização na matriz do gel também é maior $\left(>100 \mathrm{mg} / \mathrm{cm}^{3}\right)$ (PARASCANDOLA; BRANDUARDI; ALTERIIS, 2006).

Um dos agentes ligantes mais comuns utilizados neste processo são os grupamentos N-metilenoacrilamida (MAA), como no caso da produção de protease ácida pelo fungo Humicola lutea 131-5. O composto polietilenoglicol (PEG) é um composto inerte solúvel em água que confere o controle da porosidade da matriz (ALEKSIEVA; PETRICHEVA; KONSTANTINOV, 1998; SLOKOSKA et al., 1999).

A Figura 5 mostra um esquema de IC em gel de PVA. Geralmente se utiliza um agitador magnético (1) e um recipiente estéril (2), contendo as células microbianas, que são misturadas à solução de PVA (responsável pela formação das ligações de hidrogênio). A mistura homogeneizada é bombeada (3) até uma haste, onde é gotejada em um recipiente (6), que contém um líquido à baixa temperatura, geralmente inferior a $-10^{\circ} \mathrm{C}$. Devido à dificuldade de manipulação a baixas temperaturas, o líquido é mantido em câmara resfriada (5). O produto formado é depositado na forma de esferas no fundo do recipiente (6). 


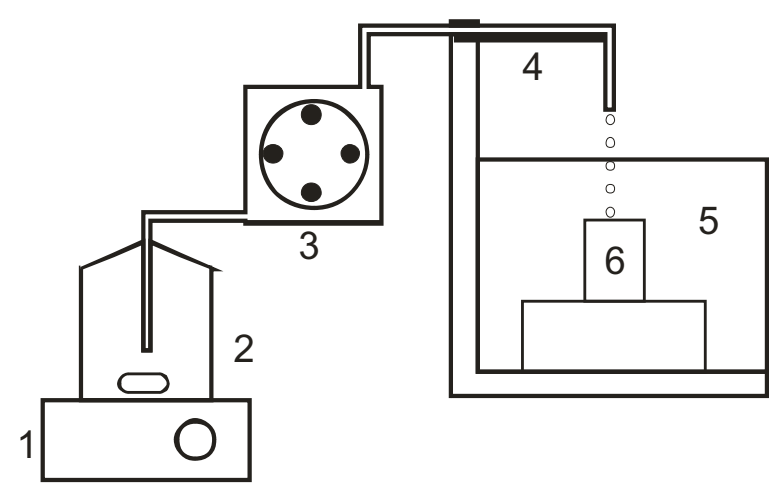

Figura 5. Esquema do procedimento de imobilização microbiana por engaiolamento em álcool polivinílico (PVA).

Song et al. (2005) modificaram o método de imobilização em PVA pela adição de goma xantana e surfactantes; utilizando uma técnica baseada nos métodos de engaiolamento e encapsulação, denominada imobilização híbrida (Figura 6). Esta imobilização foi utilizada para a remoção de nitrato de águas residuais pelo Ochrobactrum anthropi SY520 e apresentou uma eficiência maior (181\%) do que as células imobilizadas pelos métodos tradicionais.

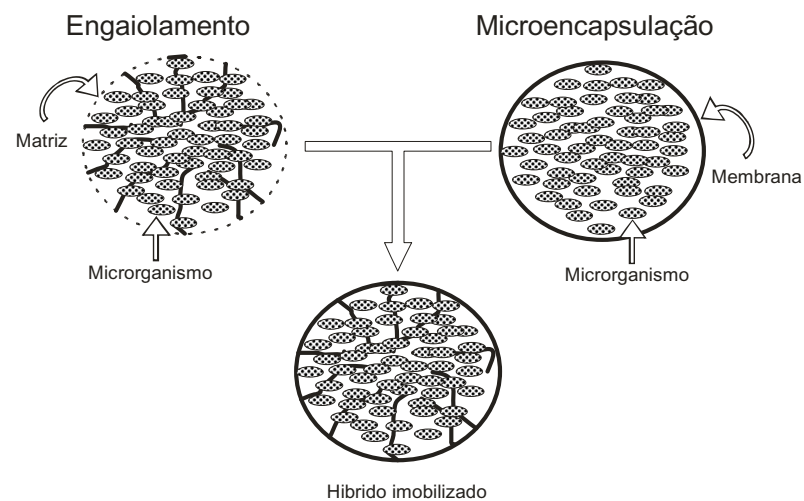

Figura 6. Ilustração da técnica de imobilização híbrida a partir dos métodos de engaiolamento e encapsulação.

A produção de polimetilgalacturonase por $A$. niger (GERIN; ASTHER; ROUXHET, 1997) imobilizado em alginato de cálcio foi 18 vezes maior do que o uso dos esporos livres no cultivo. A atividade enzimática apresentou boa estabilidade com o prolongamento do pico por mais tempo (ANGELOVA; SHEREMETSKA; LEKOV, 1998).
A produção de protease alcalina por Teredinobacter turnirae, imobilizado em alginato de cálcio, apresentou um rendimento maior (187 vezes) do que os cultivos com células livres, tendo sido reutilizado em 5 ciclos consecutivos (BESHAY, 2003).

Patil et al. (2006) compararam o uso de Bacillus sp. imobilizado em espumas de poliuretano e alginato de cálcio, na degradação de $o$-ftalato (componente das resinas de PVC). Observaram que as células imobilizadas em alginato apresentaram 13 repetições bem sucedidas contra 25 repetições com as imobilizadas em poliuretano, as quais foram mais resistentes (PATIL et al., 2006). Resultados semelhantes foram obtidos na produção de antibióticos por Streptomyces clavuligerus imobilizado nestes mesmos suportes (DEVI; SRIDHAR, 2000), comprovando a importância da escolha do suporte e do processo de imobilização.

\section{Imobilização natural de células microbianas (auto-imobilização)}

Os fungos são microrganismos eucariontes que apresentam diferentes aspectos morfológicos, dependendo do ambiente em que se encontram. Geralmente, podem ser encontrados na forma de esporos ou de filamentos, e, quando submetidos a certas condições de crescimento, tendem a formar aglomerados de micélios, que geralmente adotam um formato esférico, os quais são comumente denominados "pellets" (BRAUN; VECHTLIFSHITZ, 1991), (WANG et al., 2005).

As condições de cultivo interferem nas características físico-químicas e morfológicas das hifas e na tendência destas em formar agregados celulares ou não. A formação de "pellets" pode ser coagulativa, quando proveniente de um aglomerado de esporos na fase inicial de cultivo; como no caso do Aspergillus niger e Aspergillus oryzae. Outra formação é a não-coagulativa, na quala formação do "pellet" é proveniente de um único esporo, o que acontece nos cultivos de alguns actinomicetos do 
gênero Streptomyces (YANG et al., 1992; NIELSEN et al., 1995; CARLSEN et al., 1996; ZINDARSIC; PAVKO, 2001).

As variações físico-químicas observadas em nível macroscópico influenciam a formação de agregados celulares afetando diretamente o metabolismo celular e a produção de metabólitos. Estes agregados são considerados como auto-imobilização celular, a qual é influenciada pela quantidade de inóculo, pelas forças mecânicas empregadas durante a fermentação, pelos componentes e pela tensão superficial do meio de cultivo., assim como pela presença de $\mathrm{O}_{2}$ dissolvido (ZINDARSIC; PAVKO, 2001; FENG et al., 2003).

Em alguns casos, o estado morfológico é determinante para obtenção do metabólito de interesse, como no caso da produção de penicilina por Penicillium chrysogenum (NIELSEN et al., 1995), a qual é maior com o uso de micélios livres no meio de cultivo. Outro metabólito de interesse é a produção de ácido cítrico pelo fungo Aspergillus niger, o qual ocorre quando este microrganismo se encontra na forma de "pellets" (BEROVIC et al., 1991).

Amorfologia também afeta diretamente a reologia do meio de cultivo, considerando-se que os caldos fermentados com fungos filamentosos apresentam maior viscosidade aparente devido a maior secreção de EPS para o meio extracelular, resultando em um comportamento não-Newtoniano. Portanto, alguns dos parâmetros destes processos como agitação, transferência de massa, homogeneidade do meio e remoção do $\mathrm{CO}_{2}$ formado, podem ser prejudicados pelo estado morfológico da cepa utilizada (ZINDARSIC; PAVKO, 2001).

A viscosidade do meio também afeta as operações unitárias envolvidas nos bioprocessos, como o escoamento do mosto por tubulações, a agitação em tanques, a adição de $\mathrm{O}_{2}$, a centrifugação, a filtração e a secagem, entre outros. Por outro lado, na presença de "pellets", a viscosidade é menor e ocorre um comportamento mais ou menos Newtoniano (FREEMAN; LILLY, 1998; WANG et al., 2005).
O fungo entomopatogênico Metarhizium anisopliae é produtor de destruxina, um peptídeo cíclico responsável pelo controle de insetos em grãos armazenados. O tamanho do "pellet" formado influencia o rendimento da produção, sendo $2,0 \mathrm{~mm}$ de diâmetro estabelecido como ótimo (FENG et al., 2003). A formação de "pellet" é muitas vezes desejada por facilitar a separação sólido/líquido na fermentação e pode ser induzida em culturas submersas com a diminuição da quantidade de inóculo, da temperatura e da concentração de nitrogênio (NIELSEN, et al. 1995; FUJITA et al., 2000).

Outro exemplo bastante comum de auto-imobilização é a habilidade de alguns microrganismos de formarem agregados com partículas sólidas encontradas naturalmente, como o solo, ou até mesmo favorecerem processos de co-imobilização com outros microrganismos. Este tipo de IC é utilizado com sucesso nos processos de biorremediação que envolvem bactérias como Bacillus subtilis e Escherichia coli (YASUDA et al., 2003). Existem ainda os casos de co-imobilização, nos quais bactérias aeróbias e anaeróbias acabam formando agregados muito eficientes na degradação de compostos xenobióticos (PENG; BLY, 1998). A co-imobilização das microalgas Chlorela sp. e Azospirillum brasilense para remoção de fósforo de águas residuais também foi descrita na literatura, como um método eficiente de co-imobilização de bactérias que atuam na remoção de cargas elevadas de polifosfatos (HERNANDEZ; DE-BASHAN; BASHAN, 2006).

\section{Floculação e contenção de células microbianas em membranas}

Apesar das grandes vantagens apresentadas pelos métodos de IC descritos anteriormente, a floculação e a contenção de células entre membranas também têm sido utilizadas em processos industriais. A floculação consiste na formação de agregados 
celulares em suspensão, associada a uma rápida sedimentação de maneira natural, ou na presença de agentes floculantes ou ligantes. Dessa maneira, a floculação pode ser considerada como uma das técnicas mais promissoras de imobilização a serem utilizadas em larga escala, devido ao grande potencial de formar agregados celulares nos reatores de leito fixo e fluidizado ou tanques com agitação (FREEMAN; LILLY, 1998).

A prática da floculação é utilizada principalmente na indústria de bebidas, uma vez que a floculação das células de Saccharomyces cerevisiae afeta positivamente o tempo da fermentação, facilita a remoção das células e contribui para o aumento da qualidade da cerveja.

Hsu, Speers e Paulson (2001) descreveram os mecanismos que ocasionaram a formação de sedimentos por $S$. cerevisiae como conseqüência das interações que envolvem a composição da parede celular, o $\mathrm{pH}$ da solução, o $\mathrm{O}_{2}$ dissolvido, o estado reprodutivo da célula e a composição do meio de cultura. A Tabela 3 cita as vantagens do uso de células imobilizadas na produção de bebidas.

Tabela 3. Vantagens do uso de células imobilizadas sobre as células livres na produção de bebidas.

\begin{tabular}{lc}
\hline Vantagens & Referências \\
\hline $\begin{array}{l}\text { Aumento do período de tempo da atividade e estabilidade do biocatalizador. } \\
\text { Elimina as fases de adaptação celular e favorece processos fermentativos contínuos, }\end{array}$ & PILKINGTON et al., 1998. \\
diminuindo os custos e o tempo de produção. & YOO et al., 1996. \\
Aumento da afinidade do microrganismo pelo substrato. & 1989 \\
Aumento da tolerância à concentrações elevadas de substratos e compostos tóxicos. & JAMAI, et al., 2001. \\
Possibilita a fermentação em temperaturas mais baixas. & MELZOCH; RYCHTERA; \\
Fácil recuperação dos produtos e separação celular do mosto. & HABOVA, 1994 \\
Regeneração e reuso do biocatalizador sem remoção do mesmo do tanque fermentativo. & CHAMPAGNE; LACROIX; \\
$\begin{array}{l}\text { Redução do risco de contaminação microbiológica, devido à alta concentração de } \\
\text { células. }\end{array}$ & SODINI-GALLOT, 1994 \\
Redução do tempo de maturação de alguns produtos. & FREMAN; LILLY, 1998. \\
\hline
\end{tabular}

O princípio do método de imobilização entre membranas é baseado no confinamento da célula entre duas membranas permeáveis. Pode ocorrer o engaiolamento das células em microcápsulas, contenção em membranas filtrantes ou também interação das mesmas na superfície de dois líquidos não-miscíveis. Esta tecnologia é a mais empregada na produção de vinhos e em fermentações contínuas que requerem a reciclagem de células (KARGUPTA, 1998). A desvantagem está no uso de membranas micro-porosas que limitam a transferência de massa, impõem resistência à passagem do fluído e aumentam o intumescimento devido ao crescimento celular no interior da membrana (LEBEAU; JOUENNE; JUNTER, 1998).

Demaneira geral, todososmétodos de imobilização induzem alterações no crescimento, na fisiologia e na atividade metabólica de bactérias, leveduras e fungos (WALSH; MALONE, 1995), (NORTON et al., 1995; JUNTER; JOUENNE, 2004,), conforme os parâmetros descritos na Tabela 4. 
Tabela 4. Parâmetros de crescimento celular que podem ser modificados pela imobilização dos microrganismos.

\begin{tabular}{cc}
\hline Parâmetros & Referências \\
\hline Limitação da transferência de massa por difusão. & FREEMAN; LILLY, 1998 \\
Aumento ou diminuição da tensão superficial. & YANG et al., 1992 \\
Efeito na pressão osmótica. & JAMAI et al., 2001 \\
Redução da atividade de água. & WEST et al., 2001 \\
Dificuldades nas interações célula-célula. & PARASCANDOLA; BRANDUARDI; ALTERIS, 2006 \\
Alterações na fisiologia e morfologia celular. & SLOKOSKA et al., 2001 \\
Aumento ou diminuição da permeabilidade celular. & KRISHNAN et al., 2001 \\
Diminuição da viabilidade dos nutrientes. & SRIDEVI; SRIDHAR, 1999 \\
Crescimento de populações não-homogêneas. & SERP et al., 2000 \\
\hline
\end{tabular}

As pesquisas envolvendo microrganismos imobilizados sugerem que os microambientes formados dentro dos hidrogéis sejam responsáveis pelas mudanças na fisiologia e no comportamento metabólico. Essa responsabilidade, aliás, não pode ser atribuída à natureza química ou física dos géis (JAMAI et al., 2001).

A comparação do metabolismo de células livres e imobilizadas de leveduras demonstrou que a IC conduz a uma ativação no metabolismo energético e à diminuição do estoque de polissacarídeos estruturais, resultando em alterações do crescimento celular e aumento da afinidade com os substratos (NORTON et al., 1995). A imobilização de $S$. cerevisiae também aumentou a viabilidade celular após estocagem em baixas temperaturas, por longos períodos de tempo (MELZOCH; RYCHTERA; HALOVA, 1994).

A IC também altera os parâmetros bioquímicos considerados ótimos para a produção de metabólitos desejados. Buzás, Dallman e Szajáni (1989) observaram que o pH ótimo para a fermentação usando células livres de $S$. cerevisae era 4,0; enquanto para as células imobilizadas o valor ótimo de $\mathrm{pH}$ foi 6,8 .
Norton et al. (1995) observaram o aumento da tolerância ao etanol por células de leveduras imobilizadas e o atribuíram ao procedimento de encapsulação celular. Esse aumento pode ter ocorrido por uma possível proteção da biomassa pelo gel, ou pela modificação dos ácidos graxos da membrana, devido às limitações na difusão de oxigênio. O mesmo foi observado por Dale, Eager e Okos (1994) no processo de imobilização das células da levedura Kluyveromyces maximus.

\section{Aplicações de microrganismos imobilizados como biocatalizadores}

A IC pode ser empregada tanto na produção de metabólitos de interesse, a partir de microrganismos, quanto no uso deles como biocatalizadores, em processos "in situ". Como exemplos, podem ser citados a biodegradação de compostos xenobióticos e processos de biotransformação. A característica fundamental das células imobilizadas para o uso nestes processos é a sua alta resistência à exposição a compostos tóxicos e ambientes hostis (JUNTER; JOUENNE, 2004). 
A biodegradação de compostos aromáticos e não-aromáticos é geralmente realizada por fungos ligninolíticos produtores das enzimas lacase, manganês-peroxidase (MnP) e lignina-peroxidase (LiP). A IC é benéfica para estas enzimas, uma vez que alguns fatores ambientais como a agitação e a aeração afetam significativamente a sua produção (DEKKER; BARBOSA, 2001; ROGALSKI et al., 2005; ZHANG et al. 2005); a imobilização também prolonga a fase de secreção destas enzimas para o meio extracelular (MOREIRA et al., 1998).

O fungo $P$. chrysosporium foi imobilizado em espuma de poliuretano e utilizado em biorreatores para oxidação de hidrocarbonetos poliaromáticos (ZHENG; OBBARD, 2002), em processos de descoloração de corantes como o poly r-478(COUTO et al., 2000), e na degradação de organoclorados (SHIM; KAWAMOTO, 2002).

Por sua vez, o fungo Trametes versicolor foi imobilizado em náilon para a transformação de pentaclorofenol e 2,4-diclorofenol e houve um aumento da transformação, devido ao aumento da produção das enzimas ligninolíticas lacase e MnP, proporcionado pelas células imobilizadas (SEDARATI et al., 2003). A mineralização de pentaclorofenol e derivados foram observados nos cultivos de $P$. chrysosporium imobilizado em espuma de poliuretano (SHIM; KAWAMOTO, 2002).

Os efluentes de indústrias têxteis são usualmente tratados por meio de processos químicos e/ou físicos, os quais têm sido ineficientes para a remoção da cor, além de apresentarem problemas de adoção pelas indústrias. O tratamento destes resíduos por microrganismos imobilizados tem sido estudado, com ótimos resultados de rendimento e reprodutibilidade. Park et al. (2006) observaram que a taxa de descoloração de efluentes coloridos com células imobilizadas de Funalia trogii, permaneceu estável por sucessivos experimentos durante o período de 10 dias.

As bactérias também têm sido utilizadas nos processos de biodegradação. O Bacillus sp. foi capaz de degradar o $o$-ftalato quando imobilizado em espuma de poliuretano, visto que sua atividade catalítica continuou ativa durante 25 ciclos sucessivos (PATIL et al., 2006).

A remoção de sulfatos de águas residuais por meio de bactérias sulfato-redutoras imobilizadas em espuma de poliuretano, carvão vegetal, polietileno de baixa densidade e cerâmicas baseadas em alumínio, favoreceram as condições anaeróbias necessárias ao desenvolvimento desses microrganismos e aumentaram a resistência desses resíduos contendo altas concentrações de sulfato (SILVA et al., 2006).

A bioconversão de fenóis e derivados é geralmente limitada pela inibição do substrato e baixas taxas de conversão. A imobilização dos microrganismos em suportes sólidos, combinada com o uso de biorreatores, permitiu a recirculação do resíduo aquoso a ser tratado e melhorou significativamente o processo, como no caso da remoção de hidrocarbonetos policíclicos pelo P. chrysosporium (PAI et al., 1995; ZHENG; OBBARD, 2002; VIGGIANI et al., 2006).

A adsorção de metais pesados também tem sido beneficiada pelo uso de microrganismos imobilizados, visto que em determinadas condições o suporte também serviu como adsorvente (COSTA; FRANÇA, 1996).

Díaz et al. (2001) descreveram o uso de um consórcio de bactérias halotolerantes no tratamento de águas salinas contaminadas por derramamento de óleo. As células imobilizadas em fibras de polipropileno foram mais eficientes e apresentaram maior estabilidade diante de incrementos de salinidade e apresentaram maior viabilidade celular e desempenho em altas concentrações de $\mathrm{NaCl}$ $(180 \mathrm{~g} / \mathrm{L})$.

Nosprocessos debiotransformação, a estabilidade dos suportes à presença de co-solventes como acetona ou metanol é necessária. No caso do uso de biocatalizadores imobilizados por encapsulação ou engaiolamento, o tamanho das cápsulas formadas é determinante no tempo de reação necessário para 
a biotransformação, considerando-se que cápsulas menores (raio $\approx 0,5 \mathrm{~mm}$ ) apresentaram baixa taxa de conversão do substrato (GUO et al., 2006).

Os biocatalizadores são capazes de transformar os compostos aromáticos em menor tempo quando comparados com células livres e são capazes de tolerar altas concentrações de substrato (VELANKAR; HEBLE, 2003). T. versicolor foi utilizado nas transformações de pentaclorofenol (3510ppm) e 2,4-diclorofenol (2100ppm) mediadas pelas enzimas lacase e $\mathrm{MnP}$ e somente $5 \%$ dos compostos foram adsorvidos pela biomassa fúngica (SEDARATI et al., 2003).

\section{Considerações finais}

Como pode ser observada no presente trabalho, a imobilização de células constitui uma técnica útil e promissora para aumentar a produção de metabólitos microbianos. Também pode ser empregada em processos de transformações visando tanto a síntese química como a degradação de compostos xenobióticos, em processos de biorremediação ambiental com sucesso. Foi comprovado que o número de publicações em periódicos internacionais, que utilizaram células imobilizadas, aumentou em mais de 200\% no período de 1995 até o presente momentoem 2007, demonstrando inequivocamentea importância do uso de microrganismos imobilizados como biocatalizadores nos mais variados processos biotecnológicos.

\section{Agradecimentos}

Os autores agradecem à Fundação Araucária (Projeto 5777) pelo apoio financeiro. L.G. Covizzi e E.C. Giese também agradecem à FAPESP pelas bolsas de mestrado e doutorado concedidas.

\section{Referências}

ALEKSIEVA, P.; PETRICHEVA, E.; KONSTANTINOV, $\mathrm{H}$. Enhancement of acid proteinase production by the fungus Humicola lutea 120-5 immobilized in crosslinked poly (vinyl alcohol) mixed with poly (ethylene glycol). Process Biochemistry, London, v. 33, n. 7, p. 725-728, 1998.

ALMEIDA, C.; BRANYIK, T.; MORADASFERREIRA, P.; TEIXEIRA, J. Continuous production of pectinase by immobilized yeast cells on spent grains. Journal of Bioscience and Bioengineering, Osaka, v. 96, n. 6, p. $513-518,2003$.

ANGELOVA, M.; SHEREMETSKA, P.; LEKOV, M. Enhanced polymethylgalacturonase production from Aspergillus niger 26 by calcium alginate immobilization. Process Biochemistry, London, v. 33, n. 3, p. 299-305, 1998.

BERGMAIER, D.; CHAMPAGNE, C. P.; LACROIX, C. Growth and exopolysaccharide production during free and immobilized cell chemostat culture of Lactobacillus rhamnosus RW-9595M. Journal of Applied Microbiology, Oxford, v. 98, n. 2, p. 272-284, 2005.

BEROVIC, M.; CIMERMAN, A.; STEINER, W.; KOLOINI, T. Submerged citric-acid fermentation - Rheological properties of Aspergillus niger broth in a stirred tank reactor. Applied Microbiology and Biotechnology, Berlin, v. 35, n. 5, p. 579-581, 1991.

BESHAY, U. Production of alkaline protease by Teredinobacter turnirae cells immobilized in Ca-alginate beads. African Journal of Biotechnology, Amsterdam, v. 2, n. 3, p. 60-65, 2003.

BOZA, Y.; COSTA, F. A. A.; SCAMPARINI, A. Exopolysaccharide production by encapsulated Beijerinckia cultures. Process Biochemistry, London, v. 39, n. 3, p. 1201-1209, 2004.

BRAUN, S; VECHT-LIFSHITZ, S. E. Mycelial morphology and metabolite production. Trends in Biotechnology, Amsterdam, v. 9, n. 2, p. 63-68, 1991.

BUZÁS, Z. S.; DALLMAN, K.; SZAJÁNI, S. Influence of $\mathrm{pH}$ on the growth and ethanol production of free and immobilized Saccharomyces cerevisiae cells. Biotechnology and Bioengineering, New York, v. 34, n. 6, p. 882-884, 1989.

CARLSEN, M.; SPOHR, A. B.; NIELSEN, J.; VILLADSEN, J. Morphology and physiology of an alpha Amylase producing strain of Aspergillus oryzae during batch cultivations. Biotechnology and Bioengineering, New York, v. 49, n. 3, p. 266-276, 1996. 
CHAMPAGNE, C. P.; LACROIX, C.; SODINIGALLOT, I. Immobilized cell technologies for the dairy industry. Critical Reviews in Biotechnology, Boca Raton, v. 14, n. 2, p. 109-134, 1994.

COSTA, A. C. A.; FRANÇA, F. P. The use of seaweeds as immobilization supports for microorganisms used in continuous cadmium biosorption. Biotechnology Techniques, Kew, v. 10, n. 10, p. 761-766, 1996.

COUTO, S. R.; RIVELA, I.; MUÑOZ, M. R.; SANROMÁN, A. Ligninolytic enzyme production and the ability of decolourisation of Poly R-478 in packedbed bioreactors by Phanerochaete chrysosporium. Bioprocess and Biosystems Engineering, Berlin, v. 23, n. 3, p. 287-293, 2000.

DALE, A.; EAGER, A. M.; OKOS, M. R. Osmotic inhibition of free and immobilized $K$. marxianus: Anaerobic growth and ethanol productivity in whey permeate concentrate. Process Biochemistry, London, v. 29, n. 7, p. 535-544, 1994.

DEKKER, R. F.H.; BARBOSA,A.M. The effects of aeration and veratryl alcohol on the production of two laccases by the ascomycete Botryosphaeria sp. Enzyme and Microbial Technology, New York, v. 28, n. 1, p. 81-88, 2001.

DEVI, S.; SRIDHAR, P. Production of cephamycin C in repeated batch operations from immobilized Streptomyces clavuligerus. Process Biochemistry, London, v. 36, n. 3, p. 225-231, 2000.

DÍAZ, E.; FERNÁNDEZ, A.; PRIETO, M. A.; GARCÍA, J. L. Biodegradation of aromatic compounds by Escherichia coli. Microbiology and Molecular Biology Reviews, New York, v. 65, n. 4, p. 523-569, 2001.

DOMÍNGUEZ, A.; COUTO, S. R.; SANROMÁN, A. Amelioration of ligninolytic enzyme production by Phanerochaete chrysosporium in airlift bioreactors. Biotechnology Letters, Dordrecht, v. 23, n. 6, p. 451-455, 2001.

FENG, K-C.; ROU, T-M.; LIU, B-L.; TZENG, YM.; CHANG, Y-N. Effect of fungal pellet size on the high yield production of destruxin B by Metarhizium anisopliae. Enzyme and Microbial Technology, New York, v. 34, n. 1, p. 22-25, 2003.

FENICE, M.; FEDERICI, F.; SELBMANN, L.; PETRUCCIOLI, M. Repeated-batch production of pigments by immobilized Monascus purpureus. Journal of Biotechnology, Amsterdam, v. 80, n. 3, p. 271-276, 2000.

FREEMAN, A.; LILLY, M. D. Effect of processing parameters on the feasibility and operational stability of immobilized viable microbial cells. Enzyme and Microbial Technology, New York, v. 23, n. 5, p. 335-345, 1998.
FUJITA, M.; ERA, A.; IKE, M.; SODA, S.; MIYATA, N.; HIRAO, T. Decolorization of heat-treatment liquor of waste sludge by a bioreactor using polyurethane foam-immobilized white rot fungus equipped with an ultramembrane filtration unit. Journal of Bioscience and Bioengineering, Osaka, v. 90, n. 4, p. 387-394, 2000.

GARBAYO, I.; VILCHEZ, C.; NAVA-SAUCEDO, J. E.; BARBOTIN, J. N. Nitrogen, carbon and lightmediated regulation studies of carotenoid biosynthesis in immobilized mycelia of Gibberella fujikuroi. Enzyme and Microbial Technology, New York, v. 33, n. 5, p. 629634, 2003.

GERIN, P.A.; ASTHER, M.; ROUXHET, P. G. Peroxidase production by the filamentous fungus Phanerochaete chrysosporium in relation to immobilization in "filtering" carriers. Enzyme and Microbial Technology, New York, v. 20, n. 4, p. 294-300, 1997.

GUO, X-L.; DENG, G.; XU, J.; WANG, M-X. Immobilization of Rhodococcus sp. AJ270 in alginate capsules and its application in enantioselective biotransformation of trans-2-methyl-3-phenyloxiranecarbonitrile and amide. Enzyme and Microbial Technology, New York, v. 39, n. 1, p. 1-5, 2006.

HERNANDEZ, J-P.; DE-BASHAN, L. E.; BASHAN, Y. Starvation enhances phosphorus removal from wastewater by the microalga Chlorella spp. coimmobilized with Azospirillum brasilense. Enzyme and Microbial Technology, New York, v. 38, n. 1-2, p. 190198, 2006.

HSU, J. W.; SPEERS, R. A.; PAULSON, A. T. Modeling of orthokinetic flocculation of Saccharomyces cerevisiae. Biophysical Chemistry, Amsterdam, v. 94, n. 1-2, p.4758, 2001.

JAMAI,L.; SENDIDE,K.;ETTAYEBI,K.;ERRACHIDI, F.; HAMDOUNI-ALAMI, O.; TAHRI-JOUTI, M. A.; MCDERMOTT, T.; ETTAYEBI, M. Physiological difference during ethanol fermentation between calcium alginate-immobilized Candida tropicallis and Saccharomyces cerevisiae. FEMS Microbiology Letters, Amsterdam, v. 204, n. 2, p. 375-379, 2001.

JUNTER, G. A.; JOUENNE, T. Immobilized viable microbial cells: from the process to the proteome in leader or the cart before the horse. Biotechnology Advances, New York, v. 22, n. 8, p. 633-658, 2004.

KALUSKAR, V. M.; KAPADNIS, B. P.; JASPERS, C.; PENNINCKX, M. J. Production of laccase by immobilized cells of Agaricus sp.: induction effect of xylan and lignin derivatives. Applied Biochemistry and Biotechnology, Clifton, v. 76, n. 3, p. 161-170, 1999. 
KARGUPTA, K.; DATTA, S.; SANYAL, S. K. Analysis of the performance of a continuous membrane bioreactor with cell recycling during ethanol fermentation. Biochemical Engineering Journal, Amsterdam, v. 1, n. 1, p. 31-37, 1998.

KIM, S. J.; SHODA, M. Decolorization of molasses and a dye by a newly isolated strain of the fungus Geotrichum candidum Dec 1. Biotechnology and Bioengineering, New York, v. 62, n. 1, p. 114-119, 1999.

KOURKOUTAS, Y.; KOMAITIS, M.; KOUTINAS, A. A.; KANELLAKI, M. Wine production using yeast immobilized on apple pieces at low and room temperatures. Journal of Agricultural and Food Chemistry, Easton, v. 49, n. 3, p. 1417-1425, 2001.

KOURKOUTAS, Y.; MCERLEAN, C.; KANELLAKI, M.; HACK, C. J.; MARCHANT, R.; BANAT, I. M.; KOUTINAS, A. A. High-temperature wine making using the thermotolerant yeast strain Kluyveromyces marxianus IMB3. Applied Biochemistry and Biotechnology, Clifton, v. 112, n. 1, p. 25-35, 2004.

KRISHNAN, A. S.; LALITHA, R. G. A.; MISRA, A. M. C.; KARANTH, N. G. Physiological and morphological changes in immobilized L. Plantarum ncim 2084 cells during repeated batch fermentation for production of lactic acid. Food Biotechnology, New York, v. 15, n. 3, p. 193-202, 2001.

LEBEAU, T.; JOUENNE, T.; JUNTER, G. A. Continuous alcoholic fermentation of glucose/xylose mixtures by co-immobilized Saccharomyces cerevisiae and Candida shehatae. Applied Microbiology and Biotechnology, Berlin, v. 50, n. 3, p. 309-313, 1998.

LUSTA, K. A.; CHUNG, I. K.; SUL, I. W.; PARK, H. S.; SHIN, D. I. Immobilization of fungus Aspergillus sp. by a novel cryogel technique for production of extracellular hydrolytic enzymes. Process Biochemistry, London, v. 35, n. 10, p. 1177-1182, 2000.

MELZOCH, K.; RYCHTERA, M.; HABOVA, V. Effect of immobilization upon the properties and behaviour of Saccharomyces cerevisiae cells. Journal of Biotechnology, Amsterdam, v. 31, n. 1, p. 59-65, 1994.

MOREIRA, M. T.; PALMA, C.; FEIJOO, O.; LEMA, J. M. Strategies for the continuous production of ligninolytic enzymes in fixed and fluidised bed bioreactors. Journal of Biotechnology, Amsterdam, v. 1, n. 66, p. 27-39, 1998.

NAVRATIL, M.; DOMENY, Z.; HRONSKY, V.; STURDIK, E.; SMOGROVICOVA, D.; GEMEINER, P. Use of bioluminometry for determination of active yeast biomass immobilized in ionotropic hydrogels. Analytical Biochemistry, New York, v. 284, n. 2, p. 394-400, 2000.
NIELSEN, J.; JOHANSEN, C. L.; JACOBSEN, M.; KRABBEN, P.; VILLADSEN, J. Pellet formation and fragmentation in submerged cultures of Penicillium chrysogenum and its relation to penicillin production. Biotechnology Progress, New York, v. 11, n. 1, p. 93-98, 1995.

NORTON, S.; WATSON, K.; D'AMORE, T. Ethanol tolerance of immobilized brewers' yeast cells. Applied Microbiology and Biotechnology, Berlin, v. 43, n. 1, p. 18-24, 1995.

OGBONNA, J. C.; MASHIMA, H.; TANAKA, H. Scale up of fuel ethanol production from sugar beet juice using loofa sponge immobilized bioreactor. Bioresource Technology, Essex, v. 76, n. 1, p. 1-8, 2000.

PAI, S-L.; HSU, Y-L.; CHONG, N-M.; SHEU, C-S.; CHEN, C-H. Continuous degradation of phenol by Rhodococcus sp. immobilized on granular activated carbon and in calcium alginate. Bioresource Technology, Essex, v. 1, n. 51, p. 37-42, 1995.

PARASCANDOLA, P.; BRANDUARDI, P.; ALTERIIS, E. D. PVA-gel (Lentikats $\AA$ ) as an effective matrix for yeast strain immobilization aimed at heterologous protein production. Enzyme and Microbial Technology, New York, v. 38, n. 5, p. 184-189, 2006.

PARK, C.; LEE, B.; HAN, E-G.; LEE, J.; KIM, S. Decolorization of acid black 52 by fungal immobilization. Enzyme and Microbial Technology, New York, v. 39, n. 3, p. 371-374, 2006.

PATIL, N. K.; VEERANAGOUDA, Y.; VIJAYKUMAR, M.; NAYAK, S.; KAREGOUDAR, T. Enhanced and potential degradation of o-phthalate by Bacillus $s p$. immobilized cells in alginate and polyurethane. International Biodeterioriation and Biodegradation, Barking, v.57, n. 2, p. 82-87, 2006.

PENG, C. A.; BLY, M. J. Analysis of xenobiotic bioremediation in a co-immobilized mixed culture system. Biochemical Engineering Journal, Amsterdam, v. 1, n. 1, p. 63-75, 1998.

PETRE, M.; ZARNEA, G.; ADRIAN, P.; GHEORGHIU, E. Biodegradation and bioconversion of cellulose wastes using bacterial and fungal cells immobilized in radiopolymerized hydrogels. Resources, Conservation and Recycling, Amsterdam, v. 27, n. 4, p. 309-332, 1999.

PILKINGTON, P. H.; MARGARITIS, A.; MENSOUR, N. A.; RUSSEL, I. Fundamentals of immobilized yeast cells for continuous beer fermentation: A review. Journal of the Institute of Brewing, London, v. 104, p. 19-31, 1998. 
PRASAD, K. K.; MOHAN, S. V.; BHASKAR, Y. V.; RAMANAIAH, S. V.; BABU, V. L.; PATI, B. R.; SARMA, P. N. Laccase production using Pleurotus ostreatus 1804 immobilized on PUF cubes in batch and packed bed reactors: influence of culture conditions. Journal of Clinical Microbiology, Washington, v. 43, n. 3, p. 301-307, 2005.

ROGALSKI, J.; SZCZODRAK, J.; JANUSZ, G. Manganese peroxidase production in submerged cultures by free and immobilized mycelia of Nematoloma frowardii. Bioresource Technology, Essex, v. 97, n. 3, p. 469-476, 2005.

SAPARRAT, M. C.; GUILLEN, F.; ARAMBARRI, A. M.; MARTINEZ, A. T.; MARTINEZ, M. J. Induction, isolation, and characterization of two laccases from the white rot basidiomycete Coriolopsis rigida. Applied and Environmental Microbiology, Washington, v. 68, n. 4, p. 1534-1540, 2002.

SEDARATI, M. R.; KESHAVARZ, T.; LEONTIEVSKY, A. A.; EVANS, C. S. Transformation of high concentrations of chlorophenols by the white-rot basidiomycete Trametes versicolor immobilized on nylon mesh. Eletronic Journal of Biotechnology, Amsterdam, v. 6, n. 2, p. 104-114, 2003.

SERP, D.; CANTANA, E.; HEINZEN, C.; VON STOCKAR, U.; MARISON, I. W. Characterization of an encapsulation device for the production of monodisperse alginate beads for cell immobilization. Biotechnology and Bioengineering, New York, v. 70, n. 1, p. 41-53, 2000.

SHIM, S. S.; KAWAMOTO, K. Enzyme production activity of Phanerochaete chrysosporium and degradation of pentachlorophenol in a bioreactor. Water Research, New York, v. 36, n. 18, p. 4445-4454, 2002.

SILVA, A. J.; HIRASAWA, J. S.; VARESCHE, M. B.; FORESTI, E.; ZAIAT, M. Evaluation of support materials for the immobilization of sulfate-reducing bacteria and methanogenic archaea. Anaerobe, London, v. 12, n. 2, p. 93-98, 2006.

SLOKOSKA, L.; ANGELOVA, M.; PASHOVA, S.; PETRICHEVA, E.; KONSTANTINOV, C. Production of acid proteinase by Humicola lutea $120-5$ immobilized in mixed photo-cross-linked polyvinyl alcohol and calciumalginate beads. Process Biochemistry, London, v. 34, n. 1, p. 73-76, 1999.

SONG, S. H.; CHOI, S. S.; KYUNGMOON, P.; YOO, Y. J. Novel hybrid immobilization of microorganisms and its applications to biological denitrification. Enzyme and Microbial Technology, New York, v. 37, n. 6 , p. $567-573,2005$.
SRIDEVI, V.; SRIDHAR, P. Effect of support materials on cephamycin C production by immobilized Streptomyces clavuligerus. Indian Journal of Experimental Biology, New Delhi, v. 37, n. 3, p. 274-279, 1999.

ÜNYAYAR S, ÜNYAYAR A, ÜNAL E. Production of auxin and abscisic acid by Phanerochaete chrysosporium ME446 immobilized on polyurethane foam. Turkish Journal of Biology, Ankara, v.24, n. 1, p. 6-11, 2000.

VASSILEV, N.; VASSILEVA, M.; AZCON, R. Solubilization of rock phosphate by immobilized Aspergillus niger. Bioresource Technology, Essex, v. 59, n. 1, p. 1-4, 1997.

VASSILEV, N.; VASSILEVA, M.; FENICE, M.; FEDERICI, F. Immobilized cell technology applied in solubilization of insoluble inorganic (rock) phosphates and P plant acquisition. Bioresource Technology, Essex, v. 79, n. 3, p. 263-271, 2001.

VELANKAR, H. R.; HEBLE, M. R. Biotransformation of (L)-citronellal to (L)-citronellol by free and immobilized Rhodotorula minuta. Electronic Journal of Biotechnology, Amsterdam, v. 6, n. 2, p. 90-103, 2003.

VIGGIANI, A.; OLIVIERI, G.; SIANI, L.; DI DONATO, A.; MARZOCCHELLA, A.; SALATINO, P.; BARBIERI, P.; GALLI, E. An airlift biofilm reactor for the biodegradation of phenol by Pseudomonas stutzeri OX1. Journal of Biotechnology, Amsterdam, v. 123, n. 4, p. 464-477, 2006.

VIGNOLI, J. A.; CELLIGOI, M. A. P. C.; SILVA, R. S. F. Development of a statistical model for sorbitol production by free and immobilized Zymomonas mobilis in loofa sponge Luffa cylindrica. Process Biochemistry, London, v. 41, n. 1, p. 240-243, 2006.

WALSH, P. K.; MALONE, D. M. Cell growth patterns in immobilization matrices. Biotechnology Advances, New York, v. 13, n. 1, p. 13-43, 1995.

WANG, L.; RIDGWAY, D.; GU, T.; MOO-YOUNG, M. Bioprocessing strategies to improve heterologous protein production in filamentous fungal fermentations. Biotechnology Advances, New York, v. 23, n. 2, p. 115129, 2005.

WEST, T. P.; STROHFUS, B. Polysaccharide production by immobilized Aureobasidium pullulans cells in batch bioreactors. Microbiological Research, Jena, v. 156, n. 3, p. 285-288, 2001.

XAVIER, J. B.; PICIOREANU, C.; ALMEIDA, J. S.; LOOSDRECHT, M. C. M. V. Monitorização e modelação da estrutura de biofilme. Boletim de Biotecnologia, São Paulo, v. 76, n. 1, p. 2-13. 2003. 
YANG, H.; REICHL, U.; KING, R.; GILLES, E. D. Measurement and simulation of the morphological development of filamentous microorganisms. Biotechnology and Bioengineering, New York, v. 39, n. 1, p. 44-48, 1992.

YASUDA, T.; KATOH, S.; INOUE, Y.; SHIMI, N. A bioremediation method based on self immobilization of cells in shallow layer of soil. Journal Chemical Engineering of Japan, Tokyo, v. 36, n. 2, p. 216-219, 2003.

YOO, I-K.; SEONG, G. H.; CHANG, H. N.; PARK, J. K. Encapsulation of Lactobacillus casei cells in liquid-core alginate capsules for lactic acid production. Enzyme and Microbial Technology, New York, v. 19, n. 5, p. 428-433, 1996.
ZHANG, Y. M.; RITTMANN, B. E.; JIANLONG, W.; YUHONG, S.; JUNTANG, Y.; HANCHANG, S.; YI, Q. High-carbohydrate wastewater treatment by IALCHS with immobilized Candida tropicallis. Process Biochemistry, London, v. 40, n. 2, p. 857-863, 2005.

ZHENG, Z.; OBBARD, J. P. Polycyclic aromatic hydrocarbon removal from soil by surfactant solubilization and Phanerochaete chrysosporium oxidation. Journal of Environmental Quality, Madison, v. 31, n. 6, p. $1842-$ 1847, 2002.

ZINDARSIC, P.; PAVKO, A. The morphology of filamentous fungi in submerged cultivations as a bioprocess parameter. Food Technology Biotechnology, Zagreb, v. 39, n. 3, p. 237-252, 2001. 